\title{
Study on Enterprise Knowledge Creation Mechanism in the Collaborative Innovation of Industry-University-Research Institutions
}

\author{
Jinying Liu \\ Institute of Management Science and Engineering,Henan University,Henan Kaifeng, P.R.China \\ ljy5678@163.com
}

Keywords: collaborative innovation of industry-university-research institutions; enterprise knowledge creation; synergy

\begin{abstract}
Creating knowledge through collaborative innovation has become an important channel to increase enterprise innovation ability. Existing researches only gave the focus of attention to the relevant abilities of knowledge recipients but neglected the correlative dependence between the relevant abilities of knowledge recipients and the knowledge transfer abilities of knowledge providers. On the basis of defining university-research institutions as the body of knowledge transfer and enterprise as the body of knowledge acquisition, knowledge acquisition, knowledge integration and development, this article analyzed enterprise knowledge creation mechanism in the collaborative innovation of industry-university-research. The model of "premise-basis-core-result" shows, in collaborative innovation, enterprise knowledge creation depends on the enterprises' knowledge demand, appropriate selection to collaborative innovation modes and partners, the synergy between the knowledge transfer ability of the science-research institution and the relevant abilities of the enterprise and the enterprises' ability of the value realization of new knowledge in the market. The research result provides a new theory tool to explain the enterprise knowledge creation mechanism and a new train of thought to comprehend the relation between the collaborative innovation of industry-university-research and the enterprise knowledge creation mechanism.
\end{abstract}

\section{Introduction}

The contribution of innovation to enterprise development has been confirmed by a large number of successful experiences in many countries. However, the core of innovation is knowledge creation and the new knowledge generated by the process of knowledge creation is the main source of independent innovation [1]. The studies found that the collaborative innovation of industry-university-research is a collaborative innovation activity that is usually carried out jointly by two kinds of basic subjects of enterprise and university-research institutions and the whole process of collaborative innovation is accompanied by knowledge flow [2]. From the perspective of knowledge flow, the university-research institutions are usually the knowledge providers, the enterprises are the knowledge recipients, and the value realization of knowledge creation ultimately depends on enhancing the knowledge creation and application capabilities of enterprises. It can be said that the collaborative innovation provides an effective platform for enterprises to create knowledge through the acquisition of external knowledge. However, how do the enterprises use this platform to realize knowledge creation? In the enterprise knowledge creation, what role do the university-research institutions play? The answers to these questions will not only help enterprises to improve the level of knowledge creation, but also help university-research institutions to improve their relationship with enterprises and then to increase the market rate of scientific research results. 


\section{Research review}

In 1990s, knowledge creation researches began to emerge and develop. Early knowledge creation researches mainly focused on a single internal enterprise, considered that knowledge creation refers to the ability and process that the overall organization creates new knowledge, spreads new knowledge both inside and outside the organization and embeds new knowledge to the products, services and systems[3-5]. With economy development, researches have come to realize that a country or a company can not possess all knowledge to adapt to rapid market changes and competitive advantage is increasingly derived from the knowledge created through the cooperation. Hardy et al. analyzed the advantages of network environment to knowledge creation, and thought that the network not only promotes the knowledge transfer in the network, but also promotes the generation of new knowledge [6]. Yao discussed the knowledge creation process on collaborative innovation of industry-university-research institutions, then identified four stages during the process of knowledge creation in collaborative innovation: knowledge gain, knowledge digestion, knowledge sharing and knowledge propagation [7]. Yao and Zhou think that the process of knowledge flow in collaborative innovation includes three stages, namely knowledge sharing, knowledge creation and knowledge transfer [8].

Essentially, collaborative innovation of industry-university-research institutions is a kind of cooperation cross heterogeneous organization. However existing researches mainly gave the focus of study on relevant abilities of knowledge recipients and ignored the interdependence between relevant abilities of knowledge recipients and knowledge output ability of knowledge providers. In view of this, considering the knowledge output influence of knowledge providers, the article would build a model of enterprise knowledge creation mechanism from the perspective of collaborative innovation of industry-university-research institutions, explore enterprise knowledge creation mechanism of collaborative innovation so as to expand and deepen the theories on both enterprise knowledge creation and collaborative innovation of industry-university-research institutions, and then provide a new theory tool to explain the enterprise knowledge creation mechanism and a new train of thought to comprehend the relation between the collaborative innovation of industry-university-research institutions and the enterprise knowledge creation mechanism.

\section{Enterprise knowledge creation mechanism in collaborative innovation of industry-university-research institutions}

\section{A.Model Building}

Enterprise knowledge creation originates from the demand of enterprises to new knowledge. When this knowledge can not be obtained internally or based on the consideration of cost benefit, enterprises begins to choose appropriate collaborative innovation partners and collaborative innovation modes according to the nature of knowledge required and the knowledge creation ability themselves. In the collaborative innovation process, university-research institutions actively organize knowledge transfer, enterprises try to acquire knowledge, digest and absorb the acquired knowledge, and integrate and develop the absorbed knowledge together with existing knowledge base, so new knowledge emerges and ultimately brings market benefit for the enterprises through knowledge application. According to the above analysis, the theoretical model of "premise-basis-core-result" on enterprise knowledge creation is built and shown in figure 1. In the model, the recognition of knowledge demand is the premise, selecting appropriate collaborative partners and modes is the basis, the knowledge transfer of the university-research institutions, the 
enterprises' knowledge acquisition, knowledge absorption of together with knowledge integration and development is the core mechanism of the enterprise knowledge creation, and the enterprises' knowledge creation and knowledge value realization is the result. In addition, it is not a simple linear relationship between these stages, and the choice of cooperative partners and the modes will be affected by the ability of enterprise knowledge creation.

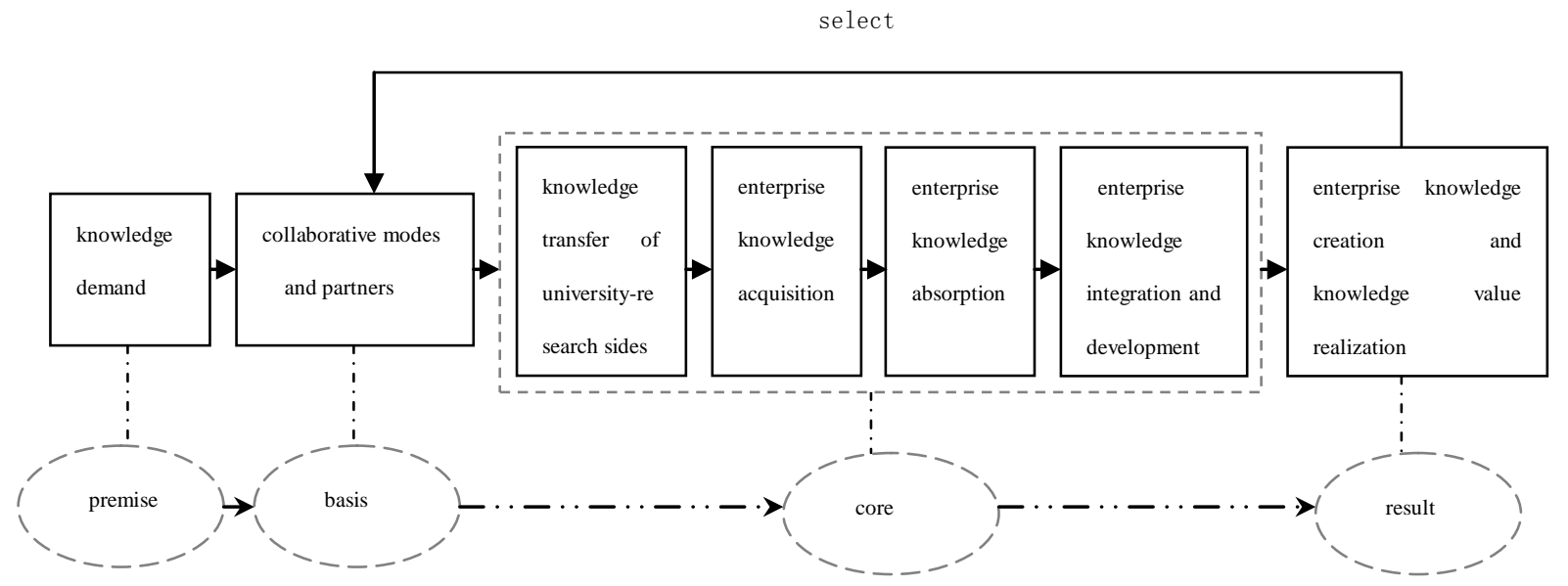

Fig.1. The model of enterprise knowledge creation mechanism in the collaborative innovation of industry-university-research institutions

\section{B.Model Analysis}

1)The premise of enterprise knowledge creation

The knowledge demand plays the guiding role to the knowledge creation and is the premise and internal driving force of enterprise knowledge creation. In the process of enterprise development, in order to enhance the competitive ability, enterprises need constantly innovate. When the existing stock of knowledge cannot meet the needs of enterprise innovation, new knowledge demand emerges. This demand promotes the enterprises to develop new knowledge system. When the enterprises cannot create new knowledge through their own abilities or the cost of acquiring knowledge from outside is less than the cost of creating knowledge through enterprises themselves, seeking external support has become an inevitable choice. Therefore, in order to accurately determine the demand for external knowledge, the enterprises need enhance the ability to predict knowledge demand and can conduct appropriate assessment on their own ability of knowledge creation.

2) The basis of enterprise knowledge creation

Choosing appropriate collaborative innovation partners and collaborative innovation modes according to the need of knowledge creation is the foundation for enterprises to carry out knowledge creation.

Firstly, the selection of collaborative innovation partners. Partner selection is the first step to carry out collaborative knowledge creation. There are two key issues that need to be noticed about partner selection in general: what is the purpose of choosing partners? What conditions should partners have? To make up the gap of knowledge is an important purpose for the enterprises to cooperate with the university-research institutions. Apart from the demand of knowledge creation, cooperation relations, communication situation with university-research institutions, technology distance, geographic distance, cultural distance, research capacity and scale of university-research institutions, knowledge output will of university-research institutions and other factors also should 
be considered by enterprises in order to select the appropriate partners of collaborative innovation.

Secondly, the selection on collaborative innovation modes. Collaborative innovation always needs to be realized through a certain mode and mode is the means of achieving collaborative innovation. Collaborative innovation modes mainly include two categories, namely formal modes and informal modes. Formal modes include technology transfer, commission development, cooperative development, jointly building an economic entity etc. Informal modes include personnel exchange, cross citation of the research results, seminars and so on. Because different collaborative innovation modes have different characteristics in innovation time, innovation cost, innovation risk, innovation achievement distribution, innovative experience accumulation and management difficulty, enterprises should consider many factors including industry effect, subject areas, knowledge characteristics, organizational and personal characteristics, enterprise scale, enterprise innovation goal, research ability of university-research institutions, geographical distance, management level and enterprise knowledge creation ability and so on in order to select the appropriate modes of collaborative innovation.

3)The core mechanism of enterprise knowledge creation

The core mechanism of enterprise knowledge creation consists of the knowledge transfer of the university-research institutions, the enterprises' knowledge acquisition, knowledge absorption and knowledge integration and development.

In the researches of the current knowledge transfer, knowledge transfer is a concept with rich connotation, which includes the knowledge transfer of intra-organization and inter-organization. To analyze the enterprise knowledge creation mechanism in the collaborative innovation of industry-university-research, this article defines university-research institutions as the body of knowledge transfer and enterprises as the body of knowledge acquisition, knowledge acquisition, knowledge integration and development.

The knowledge transfer of university-research institutions is a process which the university-research institutions express their own knowledge clearly, and transfer the knowledge to the knowledge recipients through a certain way. It means knowledge output from university-research institutions. The ability and willingness of knowledge output from university-research institutions directly influence the degree of difficulty that the knowledge recipients acquire and absorb knowledge. Moreover, inter-organizational communication and interaction mechanism will also significantly influence the effect of knowledge transfer [7].Therefore, in order to promote the knowledge transfer performance, it is necessary for the university-research institutions to increase the knowledge output willingness, constantly improve the knowledge transfer ability, choose suitable way of knowledge output and establish effective communication mechanism with the knowledge recipients.

The enterprise knowledge acquisition is a process that the enterprises acquire knowledge form the university-research institutions through a certain way on the basis of knowledge search. For knowledge creation, knowledge acquisition is one of the key links in collaborative innovation. The more the enterprises effectively acquire knowledge, the smoother the process of enterprise knowledge creation is. In addition, the knowledge recipients' knowledge discernment, knowledge search abilities, knowledge value assessment ability, knowledge acquisition way and knowledge acquisition type, and the communication mechanism and communication frequency with the knowledge providers may all be the important factors to restrict the effect of knowledge acquisition.

The enterprise knowledge absorption is a process that the enterprises analyze, understand and screen the knowledge obtained from the university-research institutions, then master the basic 
principles, using rules, constitution system and the basic characteristics of the obtained knowledge to ensure that it meets their needs. Only when the knowledge is fully internalized by the recipients, the knowledge can be fully understood and adapted, ultimately recreated and utilized effectively by the recipients [7].According to the theory of absorptive capacity, the existing knowledge base of the enterprises affects the effect of knowledge absorption. The more the prior knowledge of an enterprise, the higher the knowledge level of the internal staff, the more knowledge type, and the more the enterprises can quickly react and accurately explain the acquired knowledge, the more they can explain the diverse and complicated knowledge. According to the above analysis, the stronger the knowledge transfer ability of the university-research institutions is, the faster the absorption speed and efficiency of the enterprises to acquired knowledge can be promoted. Therefore, in order to make effective use of external knowledge, the enterprises should pay attention to the accumulation of their own knowledge, the introduction and cultivation of high-quality staff and the organizational management, increase the investment in knowledge absorption and strengthen the communication with the university-research institutions.

The enterprise knowledge integration and development is a process that the enterprises integrate their existing knowledge base with the absorbed external knowledge, then improve and develop this knowledge to create new knowledge to meet the needs of enterprise innovation. Only by integrating the knowledge of acquisition, digestion and absorption, the enterprises can create new knowledge and skills, rich knowledge reserve and increase knowledge competitiveness, which requires that the enterprises can increase investment in knowledge integration and development, build reasonable knowledge communication and sharing channels, construct reasonable learning process and incentive mechanism, mobilize the enthusiasm of the staff to carry out the integration and development of knowledge, constantly improve the integration and development ability of knowledge, so that the enterprises have the abilities to excavate, integrate, improve and develop the knowledge.

Through the above analysis, it can be found that, in the collaborative innovation, the knowledge transfer ability of the university-research institutions exists a synergistic effect with the enterprises' certain abilities including knowledge acquisition ability, knowledge absorptive ability and knowledge integration and development ability, which will influence the knowledge creation performance of the enterprises. On the one hand, if the university-research institutions do not take effective measures to support knowledge transfer, even though the abilities of enterprises on knowledge acquisition, absorption and integration and development are very high, it is also very difficult for enterprises successful acquire, absorb, integrate and develop knowledge. Especially when the complexity of the transferred knowledge is relatively high, the effect of knowledge acquisition, absorption, integration and development will be more dependent on the knowledge transfer ability of the university-research institutions. On the other hand, if the enterprises are lack of abilities of knowledge acquisition, absorption, integration and development, even though the knowledge transfer ability of the university-research institutions is very strong, it is difficult for the university-research institutions to achieve successful knowledge transfer. Above analysis shows that, in collaborative innovation, only when the knowledge transfer ability of the university-research institutions can match the relevant abilities of the enterprises, the enterprises' knowledge creation performance can be improved.

4)The result of enterprise knowledge creation

Results of enterprise knowledge creation are reflected in two aspects. The first is the generation of new knowledge. The new knowledge is specifically reflected in the increase in 
technical reserves, the increase in the number of patents or is directly applied to the relevant products, processes or projects. The second is the value realization of new knowledge in the market, which usually includes two ways, namely external transfer and internal use. The external transfer of new knowledge can bring benefit for enterprises through the patent or technology transfer. The internal use of new knowledge can mainly improve product quality or process efficiency and ultimately better meet customer needs. Therefore, in order to improve the performance of knowledge creation, the enterprises need be able to balance the internal use and external transfer.

\section{Conclusions}

Creating knowledge through collaborative innovation has become an important channel for enterprises to improve their innovation ability. The existing research has mainly focused on the abilities of the knowledge recipients, and ignores the interdependence between the relevant abilities of the knowledge recipients and the knowledge transfer ability of the knowledge providers. The model of "premise-basis-core-result" shows, in collaborative innovation, enterprise knowledge creation depends on the enterprises' knowledge demand, appropriate selection to collaborative innovation modes and partners, the synergy between the knowledge transfer ability of the university-research institutions and the relevant abilities of the enterprises and the enterprises' ability of the value realization of new knowledge in the market. Therefore, in order to improve the performance of knowledge creation, the enterprises not only need rely on their own efforts, but also need get the active support from the university-research institutions. The research result has important reference value for the enterprises and the university-research institutions to reconsider the relationship between the two parties and then take the appropriate measures to improve the performance of knowledge creation. However, this article only makes a qualitative analysis to the knowledge creation mechanism in collaborative innovation, which is not only the deficiency of this article, but also the direction of future research.

\section{Acknowledgement}

In this paper, the research was sponsored by the National Social Science Foundation of China (Project No. 16BGL036) .

\section{References}

[1]Zou B., Yu B.,Bu L.H. Study on the work mechanism of knowledge transfer between university and enterprise towards the enterprise technological innovation:a empirical study based on 370 enterprises[J]. Studies in Science of Science,2012,30(7):1048-1055.

[2]Tu Z.Z.,Gu X. Study on process of industry-university-research institute collaborative innovation based on knowledge flow. Studies in Science of Science, 2013,31(9):1381-1390.

[3]Nonaka I.The knowledge creating company[J]. Harvard Business Review,1991,6(6):96-104.

[4]Fan D.J., Guo Y.Q. A study on improving SECI pattern of knowledge innovation[J]. Journal of Northwest A\&F University (Social Science Edition),2008, 8(4):77-84.

[5]Yang C.W., Fang S.C.\& Lin J.L.Organisational knowledge creation strategies: A conceptual framework[J]. International Journal of Information Management,2010,30(3):231-238.

[6]Hardy C., Phillips N.\&Lawrence T.B. Resource, knowledge and influence: The organizational effects of interorganizational collaboration[J]. Journal of Management Studies, 2003,40(2):321-347.

[7] Yao W. Study on the knowledge creation process of university-industry collaboration[D]. 
Zhejiang University,2009.

[8]Yao Y.H., Zhou H.P. Dynamic analysis of knowledge creation system in Collaborative Innovation[J].Science \& Technology Progress and Policy,2015(4):110-117. 